\title{
Cuando escucho
}

la palabra

cultura saco mi

\section{revólver:}

\section{subjetividad y tramas de lo político en América Latina*}

Quando ouço a palavra cultura saco meu revólver: subjetividade e quadros da politica na América Latina

\author{
When I hear the word culture I \\ pull out my revolver: subjectivity \\ and frames of politics in Latin \\ America
}

\section{Resumen}

La historia política reciente de América Latina se encuentra marcada por la expresión de regímenes dictatoriales y de democracia restringida, los cuales pautaron las posibilidades de configuración de los sujetos y de su formación política. En el presente artículo nos interrogamos, con base en un corpus documental apoyado en la narrativa testimonial, sobre las modalidades de constitución de subjetividades en el contexto de las prácticas de cultura política que tuvieron lugar en América Latina a partir de 1960, en las que la violencia ha sido uno de los ejes predominantes.

\section{Palabras Clave}

Formación política, Subjetividad, Narrativa testimonial, latinoamericana.

\section{Resumo}

A história política recente da América Latina está marcada pela expressão de regimes ditatoriais y de democracia restringida, os que pautaram as possibilidades de configuração dos sujeitos e da sua formação politica. No presente artigo refletimos, com base num corpus documental apoiado na narrativa testemunhal, sobre as modalidades de constituição de subjetividades, no contexto das práticas de cultura politica que aconteceram na América Latina a partir de 1960, nas quuais a violência tem sido um dos eixes predominantes.

\section{Palavras chave}

Formação politica, cultura política, Subjetividades/ Sujeitos, Narrativa testemunhal.

\section{Abstract}

The recent political history of Latin America is marked by the expression of dictatorial regimes and restricted democracy. These phenomena guided the construction of subjects and their political training. Based on a documentary corpus and a testimonial narrative, in this article we research into the modalities of subjectivity construction within the framework of political practices taking place in Latin America since 1960, when violence has been one of the predominant issues.

\section{Keywords}

politics, subjectivity, Latin American testimonial narrative.

\section{Martha Cecilia Herrera**}

* Avances del proyecto de investigación "Narrativa testimonial, políticas de la memoria y subjetividad en América Latina". Vigencia 2013-2014 CIUP-UPN.

** Profesora titular Universidad Pedagógica Nacional. Doctora en Historia de la Educación. Directora grupo de investigación Educación y Cultura Política.
Fecha de recepción: 28 de febrero de 2014 Fecha de aprobación: 31 de mayo de 2014

Pedagogía y Saberes No. 40 Universidad Pedagógica Nacional Facultad de Educación. 2014, pp. 71-86 
"Cuando escucho la palabra cultura saco mi revólver". Así tituló el diario argentino Página 12, su primera página del 8 de noviembre de 2013, la noticia relacionada con el hallazgo de las actas de la dictadura argentina (1976-1983), en las cuales se incluían tres listados, correspondientes a 1979, 1980 y 1982, de centenares de intelectuales que incluían artistas, músicos, escritores, cineastas, poetas, psicólogos y sociólogos. Los listados fueron censurados y perseguidos por el régimen, como evidencia de la puesta en marcha de una estrategia deliberada para modificar radicalmente ciertas costumbres y formas de ver el mundo afines a la cultura que había eclosionado en los años 60, la cual abarcaba un rango bastante amplio y heterogéneo, proveniente de las vanguardias artísticas, los movimientos sociales, las organizaciones políticas, así como algunos grupos guerrilleros (que irrumpieron en el período al calor de la revolución cubana), que vehiculizaron matrices culturales diferentes a las del orden social establecido y con ellas otros proyectos de futuros posibles.

La serie de acontecimientos conexos con la noticia, a la que alude Página 12, fueron comunes a buena parte de los países de América Latina entre 1960 y 1990, bien fuese a través de las dictaduras que tuvieron lugar en el Cono Sur o de gobiernos de democracia restringida en otros países (en los que se incluye Colombia). Estos acontecimientos se enmarcan en el contexto global de la Guerra Fría y hacen parte de políticas de corte internacional, con las que se cerró el paso a proyectos diferentes al modelo capitalista en su fase neoliberal, el cual traía consigo el recorte del Estado de Bienestar bajo la hegemonía del mercado y del amansamiento de las fuerzas opositoras. Esta serie de acontecimientos tuvo repercusiones en distintas esferas de la sociedad y afectó de manera directa las culturas políticas y los procesos de subjetivación y de configuración de subjetividades políticas.

Al traer a colación la célebre frase atribuida a Hermann Wilhelm Goring, alemán nazi fundador de la Gestapo ${ }^{1}$, como la condensación del proyecto político autoritario de los nazis en materia cultural, Página 12 sitúa en el mismo reservorio de memorias sobre la violencia política los crímenes nazistas y la actuación de la dictadura argentina en contra de expresiones culturales que pudiesen anidar ideas contrarias a las del régimen impuesto. Hecho que indica el uso que

1 La cual es una versión de la frase de la obra Schlageter de Hanns Johst: "Cuando oigo la palabra cultura... iLe quito el seguro a mi Browning!" (Acto 1, Escena 1). Obra presentada en abril de 1933 para celebrar el cumpleaños número 44 de Hitler y que alude a Albert Leo Schlageter, considerado un mártir a favor de la causa nazi. La frase también llegó a ser atribuida al general franquista Emilio Mola. se le ha dado al Holocausto como tropo universal del trauma histórico en las sociedades contemporáneas y, por esta vía, la globalización que se registra en asuntos referentes a la memoria y su conjugación con espacialidades y temporalidades diferenciales que, no obstante, hacen uso del tropo del Holocausto como elemento que los emparenta ${ }^{2}$.

De esta manera, el imperativo categórico al que convocaba Adorno (1998, p. 79), respecto a que la educación de las nuevas generaciones garantizase la enseñanza moral y política de que Auschwitz no se repitiese, ha quedado tristemente desmentido por la multiplicación de fenómenos de violencia política que todavía dejan huella en la constitución de los sujetos durante el siglo xx y comienzos del XXI, y que encuentran en Auschwitz algún tipo de consonancia.

De este modo, en acontecimientos límites o determinadas coyunturas las producciones colectivas que componen las culturas políticas se ven confrontadas y atraviesan por procesos de configuración y reconfiguración, a la vez que modulan la formación política de los individuos y ponen a prueba sus formas de entender el mundo y las pautas que de allí se desprenden para sus actuaciones políticas (Ramírez, 2002). Los procesos de formación, referentes a la cultura política, entrañan una compleja relación entre el conocimiento del que se van apropiando los individuos, su propia experiencia biográfica y las relaciones que se dan dentro de los grupos sociales en los que estos llevan a cabo sus actuaciones, e inciden en las formas de configurarse como seres políticos.

Fenómenos como a los que alude el diario argentino dejan entrever los estrechos lazos entre cultura y política y, en este sentido, de qué modo los repertorios culturales que portan los sujetos interesan al poder y hasta qué punto este está dispuesto a intervenir sobre ellos, en la medida en que hacen parte de los reservorios que alimentan las culturas políticas, moldean las subjetividades y vehiculan procesos de formación política que pueden incidir en el respaldo o en la oposición a los regímenes establecidos (Cefaï, 2001, p. 98).

Desde este horizonte, en el presente artículo nos interrogamos en torno a cuáles fueron las modalidades de constitución de subjetividades, en el contexto de las prácticas de cultura política que tuvieron lugar en América Latina a partir de 1960, en donde la violencia política ha sido uno de los ejes predominantes,

2 Para Andreas Huyssen: "en la medida en que el Holocausto en tanto tropos universal de la historia traumática se desplazó hacia otros contextos no relacionados, uno siempre debe preguntarse si y de qué manera el Holocausto profundiza u obstaculiza las prácticas y las luchas locales por la memoria, o bien si y de qué manera tal vez cumple con ambas funciones simultáneamente" (2001, p. 17). 
para lo cual tomamos como base un corpus documental apoyado, en buena parte, en la narrativa testimonial. Se sostiene la hipótesis de que la violencia política desactivó los lazos sociales y políticos, y reconfiguró las subjetividades desde imaginarios que procuraron distanciarse de los idearios políticos de los años 60 y 70, modulando sujetos afines a la lógica capitalista bajo la égida del terrorismo de estado y posteriormente en clave democrática. A su vez, se señalan las posibilidades formativas de las narrativas testimoniales para contribuir a una pedagogía de la memoria de la historia latinoamericana reciente.

\section{La narrativa testimonial en América Latina y sus contextos de enunciación}

\begin{abstract}
Aunque suene cursi, cuando escuchás esas historias con el corazón, ya sos parte de ellas. Es cuando el uno se diluye en el colectivo, en el nosotros.
\end{abstract}

GoLDMAN (2012, p. 14).

La narración se considera una de las formas a través de las cuales los seres humanos damos sentido a la existencia, procesamos las experiencias y las compartimos con los otros. Autores como Ricoeur (1996; 1999) nos hablan de la identidad narrativa para denotar de qué manera la narración opera como configuración del sí mismo en una relación dialógica con el otro, contribuyendo a la configuración de la identidad personal. Begué (2002) siguiendo a Ricoeur afirma:

Todos generamos nuestra identidad narrativa en la medida en que articulamos temporalmente nuestro ídem con nuestro ipse mediante el lenguaje, cuyo primer nivel es el relato. Cada persona ejerce su identidad narrativa según la variedad de personajes que incorpora en su juego, o sea, según los diferentes modos de articular su ídem con su ipse, los cuales están siempre acompañados por identificaciones simbólicas que sirven de modelo más o menos vigente en cada momento. (p. 253)

En la constitución de la subjetividad es crucial el horizonte de valores inscrito en la historia personal, horizonte que hace parte del cúmulo de saberes y tradiciones culturales que se van decantando en los distintos contextos históricos y a los cuales accedemos a través de diversas formas de narratividad. Para Lara (1992):

El sujeto, hegelianamente vinculado a otros sujetos, interactúa en y a través del lenguaje, desde ese mismo horizonte compartido en el que se definen los espacios morales y se contextualizan nuestras elecciones. Por ello, la narratividad con la que ese sujeto se reconoce es como un largo viaje, en el que se transforman y modifican nuestras nociones e interpretaciones de vida. (p. 227)
La narrativa testimonial ha cobrado fuerza en América Latina desde los años 70, adquiriendo modalidades caracterizadas por el compromiso con las luchas sociales que se llevaron a cabo en el continente y la defensa de los proyectos políticos de izquierda que fueron perseguidos y derrotados por regímenes dictatoriales o de democracia restringida entre 1960 y 1990 (Herrera, 2012). Estas narrativas han entrado a circular en el campo cultural y político y contribuyen a moldear los sujetos en la medida en que a través de sus elaboraciones ponen en cuestión las memorias hegemónicas, difunden visiones del mundo, valores éticos y morales, así como juicios políticos sobre los acontecimientos vividos durante estas décadas. En ellas pueden estar en juego tanto memorias ejemplares en las que el pasado se convierte en un principio de acción para el presente, como memorias literales que no permiten superar el acontecimiento pasado ocluyendo el presente (Todorov, 2000).

Las características que asumió la narrativa testimonial ligada a la violencia política llevó a cuestionar los cánones establecidos entre lo que se consideraba literatura o periodismo, pero también historia, memoria o denuncia política (Ochando, 1998; Moraña, 1997). De este modo, para comprender la significación histórica del testimonio en América Latina es necesario tener en cuenta la presencia de:

Un dispositivo metadiscursivo programáticamente impulsado desde el final de los años 60, que interrelaciona dos operaciones simultáneas: convierte en literatura una serie textual que, hasta el momento, se entendía como extraliteraria - periodística, científica, política-, y la representa como "propiamente latinoamericana", en la medida en que aludía a la agitada vida política de la región -como insignia básica de la autopercepción de la época-. (García, 2013, p. 370)

Las posibilidades de enunciación de estas narrativas están articuladas con los contextos y escenarios en los cuales tienen lugar y con los canales de circulación que recorren, guardando una relación importante con las políticas de la memoria que pautan, en algunos sentidos, sus derroteros (Strejilevich, 2006). Las narrativas testimoniales son de carácter diferencial dependiendo del escenario en el cual deban ser explicitadas, no es lo mismo declarar ante un juez, una comisión de derechos humanos, una organización de familiares de presos y desaparecidos políticos, un escenario nacional o internacional, o narrar para circular en un medio artístico o literario, bien sea a través de la propia voz o la de un intermediario. Cada uno de estos escenarios marcan las condiciones de posibilidad que 
tiene el testimoniante para narrar lo vivido, explicar y explicarse lo sucedido (Herrera, 2013).

En este mismo sentido no son las mismas condiciones que se dan para el relato testimonial en cada coyuntura. En el caso argentino no es lo mismo escribir y publicar en la década del 70 con la represión encima, a hacerlo en los años 80 cuando se inician los gobiernos de transición y los relatos son valorados como fuente de denuncia para el juicio a las Juntas (con insistencia en la memoria de las víctimas), a hacerlo a principios de los 90 bajo las Leyes de Obediencia y Punto Final que reinstauraron la impunidad, o a finales de los 90 cuando emergen declaraciones de represores, o de ex-militantes que reivindican el vínculo político que tenían en los años 70 y por el que fueron perseguidos, o en el 2000 cuando la corte declara la nulidad de Leyes de Obediencia y Punto Final "que posibilitó la condena a cadena perpetua y cárcel común para un alto número de represores que aún permanecen en libertad" (Daona, 2013, p. 62).

Fernando Reati (2004), afirma que las narrativas testimoniales escritas por ex-prisioneros políticos en los años 80 en Argentina ${ }^{3}$ están marcadas por las representaciones públicas (oficiales y no oficiales) sobre el pasado reciente. Según él:

Aquellos testimonios carcelarios de los 80, de intención mayormente política y denunciatoria, estaban constreñidos por la necesidad de la autojustificación y la autodefensa frente a una memoria colectiva no siempre favorable a ellos en aquel momento, lo cual los obligaba a moldear su memoria de lo ocurrido en medio de un contexto social que todavía negaba en gran medida los prolongados efectos traumáticos de lo ocurrido. (p. 107)

Al mismo tiempo, Reati, quien es un expreso político, señala que la elaboración del trauma sufrido por los sujetos requiere de un tiempo de procesamiento que se puede apreciar en la narrativa testimonial. Así, cuando ha pasado un mayor tiempo desde la experiencia traumática los escritos cobran más posibilidades narrativas y potencian mejor la reconfiguración subjetiva del autor, en la medida en que las vivencias se articulan dentro de una historia de vida. En este sentido, alude a relatos testimoniales escritos en los años 90 por personas que estuvieron en cárceles, en

3 En Nombrar lo innombrable: violencia política y novela argentina (1975-1985), Reati (1992) analiza La larga noche de Francisco Sanctis (Humberto Costantini, 1984), Luna Caliente (Mempo Giardinelli, 1984), Cuarteles en invierno (Osvaldo Soriano, 1982), El mejor enemigo (Fernando López, 1984), Recuerdo de la muerte (Miguel Bonasso, 1984), De dioses, hombrecitos y policías (Humberto Costantini, 1984), El beso de la mujer araña (Manuel Puig, 1976), Con el trapo en la boca (Enrique Medina, 1984) y Cola de lagartija (Luisa Valenzuela, 1983). centros clandestinos de detención y/o en el exilio, en los cuales se pone en juego el recurso ficcional para dar solución a algunas de las encrucijadas que deben enfrentar los sujetos para procesar y comunicar sus vivencias respecto a la violencia política ${ }^{4}$.

Para el caso chileno, Jaume Peris (2008) destaca cómo los relatos testimoniales sobre la violencia política durante el período dictatorial se configuraron como prácticas tanto políticas, como literarias y terapéuticas, confluyendo en ellos sentidos muy diversos en relación con su función social:

\begin{abstract}
Atrapados entre diferentes discursos que definían los espacios que podrían recorrer y cuál iba a ser su valor en cada uno de ellos, los testimonios respondieron a las ideas que sobre ellos circulaban, ya fuera para confirmarlas o para modificarlas y proponer visiones nuevas sobre el propio acto de testimoniar. (p. 95)
\end{abstract}

La enunciación testimonial de los relatos debió lidiar con las dificultades de poner en relación el yo que hablaba en el testimonio, y demandaba para sí el estatuto de testigo superviviente, con el sujeto que había sido recluido en prisión o en los campos de concentración, cuya identidad había sido mutada de una manera radical ${ }^{5}$. Esto sería lo que los dotaría de singularidad y de ejemplaridad.

Al contrario de lo que parece pensar cierta crítica literaria, sería en los vacíos y los huecos que esa incapacidad asumida generó, en los testimonios, en los abruptos saltos y en las discontinuidades de su configuración narrativa, donde se cifraría no sólo la particularidad de estos textos, sino también su extraordinario valor político en tanto que hacían emerger una "nueva ética de la enunciación", anudada, precisamente, a las dislocaciones que sobre ella producía ese resto fantasmagórico del acontecimiento traumático que anida en la enunciación testimonial. (Peris, p. 59)

4 En este abanico de producción el autor analiza a Feijóo, Cristina. Memorias del río inmóvil. Buenos Aires: Clarín/Alfaguara, 2001. Paoletti, Mario. A fuego lento. Murcia: Colección Carabelas, 1993. Mala Junta. Buenos Aires: Editorial de Belgrano, 1999. Prieto, Martín. Calle de las Escuelas No. 13. Buenos Aires: Libros Perfil, 1999. Schmucler, Sergio. Detrás del vidrio. Buenos Aires: Siglo Veintiuno de Argentina Editores, 2000. Silberstein, Silvia. Bajo el mismo cielo. Buenos Aires: Sudamericana, 2002. Strejilevich, Nora. Una sola muerte numerosa. Miami: Letras de Oro, 1997.

5 Algunas de las obras mencionadas por Peris son: Valdés, $\mathrm{H}$. (1974). Tejas Verdes. Diario de un campo de concentación en Chile; Carrasco, R. (1977). Prigué, Moscú: Novosti; Witker A. (1975). Prisión en Chile. México: FCE; España, A. (1983). Dawson, Santiago de Chile: Bruguera; Villegas, S. (1974). Chile, el estadio, los crímenes de la Junta Militar. Buenos Aires: Cartago. 
En ellos puede verse de qué modo los proyectos políticos de oposición surgidos desde los años 60, así como los sujetos que en torno a ellos fueron modulados, fueron probados a sangre y fuego por las fuerzas del Estado y sectores de derecha. Sus actuaciones políticas, y en algunos casos militares, fueron enfrentadas tanto desde la anulación de su presencia en el escenario público, al quebrar las organizaciones políticas y diezmar sus filas, encarcelando, desapareciendo o asesinando a sus integrantes, como desde la propagación del terror en el conjunto de la sociedad, con el propósito de modular sujetos dóciles y propiciar la introducción de reformas macro-estructurales en distintas esferas de la sociedad.

La estrategia de aniquilamiento de la dictadura argentina es expresada en el libro del periodista Jacobo Timerman ${ }^{6}$. Secuestrado, torturado y desaparecido en 1977, Timerman pasó por cuatro centros clandestinos de detención y una vez liberado, a propósito de una amplia protesta internacional, publicó un libro en inglés, traducido posteriormente al español, denominado Preso sin nombre, celda sin número (1981), el cual se convirtió en un bestseller. El libro está estructurado en torno a sus vivencias como detenido bajo la tensión de tres planos narrativos: el relacionado con su detención y tortura, el de las evocaciones de su infancia y juventud unidas a su trayectoria religiosa (como judío) y política, y el de sus opiniones sobre la situación política argentina. Dentro de los recuerdos evocados, menciona que, cuando aún estaba en libertad, sostuvo una conversación con un oficial de la marina sobre el escalamiento de la violencia en el país, en la que pudo ver la actitud de intolerancia y la idea del exterminio hacia el oponente que estaba presente en la mentalidad de los militares en el período, y cuya afinidad con el Holocausto judío no se cansa de reiterar a lo largo del libro:

-Por eso hay que lograr la derrota política, crear las condiciones de una convivencia democrática, que la mayoría de la juventud busque sus símbolos en otro lado.

-Si exterminamos a todos, habría miedo por varias generaciones.

6 Periodista ucraniano-argentino, creó el diario La Opinión en 1971 el cual fue expropiado y editado por la dictadura con el mismo nombre durante cuatro años. Se le detuvo bajo la acusación de lavar dinero de la organización Montoneros a partir de sus nexos con el financista David Graiver. Timerman fue expulsado del país y se le retiró la ciudadanía argentina. Prestó testimonio en el año de 1984 ante la Conaped (Comisión Nacional sobre Desaparición de Personas) sobre su caso y la existencia de los centros clandestinos de detención, el cual fue incluido en el informe Nunca más.
-¿Qué quiere decir todos?

-Todos... Unos veinte mil. Y además sus familiares. Hay que borrarlos a ellos y a quienes puedan llegar a acordarse de sus nombres.

- ¿Y por qué cree que el Papa no protestará ante esa represión? Ya lo están haciendo muchos gobernantes mundiales, líderes políticos, dirigentes gremiales, científicos...

-No quedará vestigio ni testimonio. (p. 68)

Leon Rozitchner, filósofo y psicoanalista argentino, dice en el prólogo escrito para el libro Ese infierno: conversaciones de cinco mujeres sobrevivientes de la ESMA (2006), que en esta obra se da cuenta de las transformaciones sufridas por sus autoras ante una experiencia en la que ante todo prevaleció la amenaza de muerte, la cual las atravesó no solo a ellas sino al conjunto de la sociedad y cuya sombra continúa latente en la actualidad:

Es el fundamento del terror político presente aún en nuestra "democracia". Para que el neoliberalismo triunfara fue necesario que la muerte hiciera "tronar el escarmiento", como la frase que aprendimos en la escuela desde niños, y nos quedáramos solos, indefensos, desolados dentro de la sociedad misma. "A mí no me quedaba nadie, nadie. Empecé a llamar y estaban todos muertos". (p. 17)

$\mathrm{Al}$ referirse a las tensiones entre democracia y dictadura que se dieron en América Latina en los años 70, Perry Anderson (1988) afirma que las intervenciones militares violentas en Brasil, Uruguay, Argentina y Chile fueron:

Contrarrevoluciones preventivas cuya misión primordial fue la de decapitar y eliminar a una izquierda que no se resignaba al modo de producción capitalista, sino que apuntaba directamente a un socialismo que lo trascendía. Su función esencial, primordial, pues, fue la de traumatizar a la sociedad civil en su conjunto con una dosis de terror suficiente para asegurarse de que no habría ninguna tentación ulterior de reincidir en desafíos revolucionarios contra el orden social vigente; para romper cualquier aspiración o idea de un cambio social cualitativo desde abajo; para eliminar permanentemente, en suma, el socialismo de la agenda política nacional. Al mismo tiempo, su vocación secundaria fue la de restaurar las condiciones de una acumulación viable, disciplinando la mano de obra con represión, bajos salarios y deflación, promoviendo al mismo tiempo la capacidad exportadora y asegurando nuevos niveles de inversión externa, para que pudiera desarrollarse el crecimiento sin 
interrupciones redistributivas o escasez de capita-

les: esa fue la idea. (p. 8)

Estas fueron, pues, las condiciones en las cuales emergieron las narrativas testimoniales desde los años 70 en América Latina, adoptando diversos géneros y formatos, con diferentes modulaciones de acuerdo a los elementos anteriormente expuestos. En los países del Cono Sur, ellas han sido fuente de numerosos usos que sirven como materiales de denuncia y de procesos judiciales. Estas narrativas han integrado los informes de las comisiones de verdad y justicia, han sido incorporadas como fuente de análisis en materiales educativos sobre formación política, o simplemente, han circulado en librerías y puntos de venta, siendo consumidas por un público diverso. En esta medida, ellas han nutrido el acervo de memorias colectivas sobre la cultura política y sus nexos con la violencia, ayudando a ampliar las versiones y los puntos de vista sobre la historia política reciente. En Colombia, aunque el uso de las narrativas sobre violencia política no ha alcanzado todavía un lugar destacado en la agenda de las políticas públicas, sí viene cobrando importancia en los ámbitos locales.

Es a la luz de esta serie de consideraciones que nos interrogamos por los modos como la narrativa testimonial elabora las afectaciones que tuvieron los acontecimientos de violencia política y su incidencia sobre los sujetos y sus subjetividades, sobre sus formas de entender el mundo y de articularse políticamente. Además, dichos modos aluden a las enseñanzas morales y políticas, entre otros aspectos. A continuación, trataremos de dar respuesta a estos interrogantes con base en algunos relatos testimoniales, apoyándonos fundamentalmente, por problemas geográficos, en la experiencia argentina ${ }^{7}$.

\section{Algunas figuras de sujeto en la narrativa testimonial sobre la violencia política}

\section{Ustedes quieren corroer como el ácido el orden natural.}

\section{BonASSO, Recuerdo de la muerte (p. 58)}

El impacto que los acontecimientos de violencia política registrada en este período tuvo sobre los sujetos directamente afectados y sobre el conjunto de la sociedad, cobró distintas modulaciones de acuerdo a los países (Kordon y Edelman, 1986). Las narrativas señalan el despliegue de una política punitiva del

7 Los textos en los que nos vamos a detener en este apartado tienen como denominador común el de ser relatos testimoniales publicados como libros, así como algunas entrevistas, dadas por exdetenidos, las cuales están disponibles en Internet. cuerpo, que hizo uso de estrategias que buscaban la desubjetivación a través de prácticas en las que se controlaba el tiempo y el espacio; se hizo uso de la tortura física y sicológica, e incluso de la muerte, configurando sujetos dóciles que no se opusiesen a los procesos de restructuración económica y social que caracterizarían estas décadas. Frente a estas estrategias, los sujetos reaccionaron de maneras diversas poniendo en juego sus trayectorias biográficas y políticas, lidiando con el derrumbe de todos los referentes que estructuraban sus subjetividades y la derrota de los proyectos sociales, culturales y políticos que los alimentaban.

Las modalidades de violencia política ejercidas en los casos de Argentina y Chile convergieron en algunos sentidos, y de manera especial, en la emergencia de campos de concentración como lugares emblemáticos de las tecnologías activadas para su despliegue $^{8}$. No obstante, las resonancias se dieron en varias esferas de la sociedad y los sujetos fueron afectados de diferentes maneras, ya que la estrategia del terrorismo de estado iba dirigida hacia la sociedad en su conjunto. Como bien lo describe Julieta Lampasona:

\begin{abstract}
Se inicia, un proceso que apunta a desligar al sujeto de su historia, de su mundo relacional y del andamiaje social y político que lo constituye como ciudadano y sujeto de la confrontación. La proximidad -cotidiana- de la muerte, los procesos de aislamiento de los detenidos y, particularmente, la tortura -como forma de sumisión y dominio que irá mellando la capacidad de acción y creación del propio yo y sus construcciones identitarias- van configurando una realidad perturbadora que, por su violencia radical, golpea el mundo simbólico, ataca y se inscribe en la estructura psíquica, constituyendo una huella -traumática- que acecha, incluso de manera fantasmática y latente, a lo largo de la vida del sujeto. (2012, s. p.)
\end{abstract}

En primer lugar, hay que considerar que en Argentina, como en Chile y en Colombia, quienes fueron objeto de la violencia política estatal tuvieron que enfrentarse a la mirada que los agentes de dicha violencia tenían sobre ellos, calificándolos como subversivos y enemigos de la sociedad, teniendo que lidiar con las interpelaciones que estas miradas

8 En el caso de Argentina, funcionaron alrededor de 340 campos de concentración-exterminio entre 1975 y 1983, bajo el nombre de Centros Clandestinos de Detención, en todo el territorio nacional. Se estima que por ellos pasaron entre 15000 y 20000 personas de las cuales el $90 \%$ fueron asesinadas (Calveiro, 2006, p. 16). En Chile (1973-1990) se calcula que existieron alrededor de 1168 lugares entre públicos y secretos (Peris, 2008, p. 45). Se estima que pasaron entre 3000 y 5000 personas. 
hacían frente a los proyectos y a las organizaciones políticas (algunas armadas), que les habían estructurado como sujetos políticos. Interpelaciones que se desplegaron en el plano de lo social, a través de los medios de comunicación que hicieron eco del poder represivo en el plano familiar. Esto significó la desestructuración de los lazos afectivos y de las redes de solidaridad que allí tenían lugar, así como en el plano personal, lo que les implicó la pérdida de la libertad, y en el plano político, perder, en la mayoría de los casos, el contacto con sus organizaciones $\mathrm{y}$ tenerse que enfrentar de manera individual a los rigores del terror.

La imagen de la capucha es una marca imborrable sobre los detenidos/desaparecidos en América Latina durante este período, la cual ejemplifica de manera vívida la situación a la que se enfrentaban los sujetos en medio de la indefensión y el aislamiento cuando eran detenidos; un mensaje visual que quedó impreso en la memoria individual y colectiva en el continente. Miguel Bonasso (1984) en su texto Recuerdo de la muerte, una novela testimonial ${ }^{9}$, hace la siguiente descripción:

La capucha y las vendas constituyen una preocupación de los torturadores: los protegen de la mirada de la víctima. Pero cumplen otra función: encierran a la víctima en sí misma. El mundo entero ha quedado en tinieblas. Más allá de la tela basta y grasienta que cubre el rostro, hay un universo de amenazas. No están allí los compañeros, la familia, los amigos. La capucha ha suprimido toda historia $\mathrm{y}$ todo porvenir. Es un negro presente de soledad y desamparo. Y se cierne sobre el individuo como una incógnita. No sólo impide mirar afuera, obliga a mirar hacia adentro. A preguntarse si uno va a resistir. Si va a salir de la prueba siendo el mismo de antes o va a convertirse en un traidor. La capucha reduce el mundo a una sola decisión, a un único temor. Es sabia. Más sabia y menos benevolente que la muerte... Estaban juntos pero separados por las capuchas, por la imposibilidad de comunicarse que equivaldría a una confesión. Cada uno con su capucha. Metido en su carne y en su pasado. Cada uno temblando ante la expectativa del minuto siguiente. (pp. 37, 41)

9 Bonasso, militante montonero quien se exilia en México, escribe su obra basado fundamentalmente en las vivencias de Jaime Dri, el Pelado; un militante montonero secuestrado en Uruguay, trasladado clandestinamente a Argentina y a la ESMA, aunque también se apoya a veces en algunos testimonios y documentos de prensa para darle mayor verosimilitud a su relato. Escrita entre 1980 y 1983, antes de que terminase la dictadura. A pocas semanas de la edición argentina, vendió 5000 ejemplares y en la actualidad las ventas superan los 200000 ejemplares.
Pilar Calveiro estuvo detenida en diversos campos de concentración durante un año y medio, pudiéndose exiliar posteriormente en México, en donde estudió ciencias políticas, elaboró una tesis doctoral sobre el poder concentracionario en Argentina, que derivó en su conocido libro Poder y desaparición (2006), en donde se apoyó, para sus análisis, en diversos testimonios. En una entrevista, Pilar se refiere a las acepciones que tenía la palabra subversivo para las fuerzas armadas y como esta encarnaba cuando hacía alusión a las mujeres:

Yo diría que, en términos generales, para ellos la "subversión" era "peligrosa" no solamente en términos políticos. Lo que llamaban sedición tenía que ver con la ruptura de valores morales, familiares, religiosos. La subversión era algo que iba más allá de lo político. Yo creo que aun en su visión muy elemental tenían razón. Efectivamente nuestra generación se había planteado algo más que el problema del poder del Estado o de cuál era el sistema político con el que se debía regir la sociedad; se planteaba también otras formas de abordar la relación familiar, la relación de pareja, la paternidad y la maternidad, la religiosidad; toda esa serie de cuestionamientos que se dieron a fines de la década de los sesenta y que modificaban el lugar de la mujer en la sociedad. Entonces la visión que los militares tenían de las mujeres estaba muy ligada a esto; las veían como doblemente subversivas, tanto del orden político, como del orden familiar. Habían roto con el lugar que les tocaba de madres y esposas para lanzarse, "seguramente", al sexo desenfrenado. En mi primer testimonio ante la Conadep, yo contaba que en Aeronáutica, durante la tortura, simultáneamente me preguntaban cosas tan disímiles y absurdas como cuál era la dirección adonde vivía Firmenich y a cuántas orgías había asistido. (Moreno, 2000, s. p.).

El otro/el sí mismo se ve confrontado desde múltiples ángulos, en los centros de detención el nombre propio desaparece, ahora se es un número que cuando se nombra recuerda el sistema carcelario y el avasallamiento de la voluntad del sujeto, quebrando su autoestima, su dignidad y los referentes que lo ataban a su trayectoria biográfica anterior.

Cuando me robaron el nombre

fui una fui cien fui miles

$\mathrm{y}$ no fui nadie.

$\mathrm{NN}$ era mi rostro despojado

de gesto de mirada de vocal [...]

Camino mi desnudez numerada

en fila sin ojos sin yo

con ellos sola

desangrado mi alfabeto

por cadenas guturales 
por gemidos ciudadanos de un país

sin iniciales.

\section{NORA STREJILEVICH (2008)}

Pero también está el nombre de guerra, aquel que cuando se nombra recuerda la comunidad política de pertenencia y todo lo que evoca: las razones políticas de haber sido detenido, el desconocimiento de los nombres reales de sus compañeros o de sus dirigentes, la posibilidad de la traición... En el caso de algunos detenidos en los campos clandestinos en Argentina, también están los nuevos nombres que adquieren a través de papeles de identidad, falsificados por los militares, con los cuales son trasladados a otros lugares, a otros países, y que cuando se nombra convoca una identidad dada por el victimario con propósitos ajenos a la voluntad de los secuestrados.

En el primer capítulo del libro Preso sin nombre, celda sin número (1981) se deja al descubierto, a través de una gran maestría narrativa, el aislamiento y la soledad que el autor enfrentó, así como los esfuerzos de reconfiguración subjetiva. Cuando Timerman narra sus sensaciones sobre el lugar de encierro indica al lector las circunstancias de desorden espacio-temporal que atraviesa, a la vez que trata de anclarse en un recuerdo colectivo que le dé sentido a su actual condición.

La celda es angosta. Cuando me paro en el centro, mirando hacia la puerta de acero, no puedo extender los brazos. Pero la celda es larga. Cuando me acuesto, puedo extender todo el cuerpo. Es una suerte, porque vengo de una celda en la cual estuve un tiempo- ¿ ¿cuánto?- encogido, sentado, acostado con las rodillas dobladas. La celda es muy alta. Saltando, no llego al techo. Las paredes blancas, recién encaladas. Seguramente había nombres, mensajes, palabras de aliento, fechas. Ahora no hay testimonios, ni vestigios. (p. 17)

La figura del sujeto fragmentado que requiere del otro para reconstruir su identidad tanto en el plano individual como en el colectivo es uno de los tropos más persistentes en las narrativas. Este otro oscila entre múltiples imágenes, cobra a veces la figura del otro como ser corriente, el ser humano, otras veces aparece como el otro compañero-militante, otras veces es el otro victimario, siempre avizorado parcialmente y desde una amenazante ambigüedad.

En el relato de Timerman, sus descripciones de la relación entablada con otro prisionero, a través de la mirilla de la celda, rescatan los rasgos del ser humano con talento literario y por encima de cualquiera otra experiencia. Al describir las imágenes que capta por la pequeña ventana y con las cuales busca restablecer las partes del cuerpo del otro, vistas de manera parcial y fugaz, es como si buscase construir su identidad fragmentada en un recurso en el cual la mirada se convierte en el punto clave para guardar esperanzas, para reconfortarse en medio del dolor, para tener contacto con ese otro, prisionero, que le puede ayudar a reconstruir su unidad, para saber que él "no era el último ser humano sobre la Tierra en un Universo de guardianes torturadores”.

Trato de llenarme del espacio que veo. Hace mucho que no tengo sentido de las distancias y de las proporciones. Siento como si me fuera desatando.... Pero hace ya mucho tiempo - ¿cuánto?- que no tengo una fiesta de espacio como ésta. Ahora apoyo la oreja, pero no se escucha ningún ruido. Vuelvo entonces a mirar. Él está haciendo lo mismo. Descubro que en la puerta frente a la mía también está la mirilla abierta y hay un ojo. Me sobresalto: me han tendido una trampa. Está prohibido acercarse a la mirilla, y me han visto hacerlo. Retrocedo, y espero. Espero un Tiempo, y otro Tiempo, y más Tiempo. Y vuelvo a la mirilla. Él está haciendo lo mismo. Y entonces tengo que hablar de ti, de esa larga noche que pasamos juntos, en que fuiste mi hermano, mi padre, mi hijo, mi amigo. ¿O eras una mujer? Y entonces pasamos esa noche como enamorados. Eras un ojo, pero recuerdas esa noche, ¿no es cierto? Recuerdo perfectamente que parpadeabas, y ese aluvión de movimientos demostraba sin duda alguna que yo no era el último ser humano sobre la Tierra en un Universo de guardianes torturadores. [...] De pronto te apartabas y volvías. Al principio me asustaste. Pero enseguida comprendí que recreabas la gran aventura humana del encuentro y el desencuentro. Y entonces jugué contigo...

Era tan nítida la separación entre la vida y la soledad, que sabiendo que tú estabas ahí, no podía mirar hacia la celda, Pero tú me perdonaste, porque seguías vital y móvil. Yo entendí que me estabas consolando, y comencé a llorar. En silencio, claro... Pero tú viste que lloraba, ¿verdad?, lo viste sí. Me hizo bien llorar ante ti... contigo pude llorar serena y pacíficamente. Más bien, es como si uno se dejara llorar. Como si todo se llorara en uno, y entonces podría ser una oración más que un llanto... Tú me enseñaste, esa noche, que podíamos ser Compañeros del Llanto. (1981, pp. 19-21)

La figura del desaparecido es sin duda una de las más complejas por sus múltiples despliegues e interpelaciones (Gatti, 2008) y porque representa de la mejor manera el proyecto del terrorismo de Estado durante esas décadas en América Latina. Tenemos la declaración dada por las fuerzas armadas argentinas, cuando se empezó a preguntar por las personas que 
habían sido desaparecidas, siendo secuestradas y llevadas a cárceles o a campos de detención clandestinos y de quienes no se daba noticia ninguna a nivel oficial. El régimen afirmó que estas personas no estaban ni vivas ni muertas lo que conducía a que los reclamos en torno a su desaparición no tuviesen sustento $^{10}$. Existe una histórica declaración de Videla, reproducida por el diario Clarín el 14 de diciembre de 1979, sobre la figura del desaparecido:

¿Qué es un desaparecido? En cuanto éste como tal, es una incógnita el desaparecido. Si reapareciera tendría un tratamiento X, y si la desaparición se convirtiera en certeza de su fallecimiento tendría un tratamiento Z. Pero mientras sea desaparecido no puede tener ningún tratamiento especial, es una incógnita, es un desaparecido, no tiene entidad, no está, ni muerto ni vivo, está desaparecido. (Perfil, 2013)

Cuando el desaparecido no es asesinado hay dos posibilidades de que reaparezca y salga a la luz pública: se puede deambular por las calles o visitar a los familiares estando todavía en condición de desaparecido. Este es el caso de varios de los prisioneros sacados del encierro para ser llevados a las ciudades con propósitos varios; en unos casos, podía ser para marcar algún compañero, en otros para ir de visita a sus casas o para trabajar bajo libertad vigilada ${ }^{11}$, como parte de un proceso de recuperación al que fueron sometidos algunos secuestrados.

En aquella ocasión de la salida a Parque Patricios hacía meses que no veía la calle. Cuando me sacaron la venda, ya entrando a la ciudad, me sentí como un turista que por primera vez llega a París y todo le produce asombro. Estaba ansioso por ver si la ciudad seguía como la recordaba o si algo había cambiado. Esa experiencia profundizó, tal vez más que ninguna otra, mi comprensión de lo que significa estar desaparecido. La sensación de sentirse perdido para el mundo es muy difícil de describir. Todavía hoy me cuesta poner en palabras lo que sentía entonces; tal vez la misma perplejidad de quien hoy lee este relato es la que sentía yo... No era que el mundo había desaparecido para nosotros sino

10 La multiplicación de casos que presentó la desaparición forzada de personas como modalidad en distintas partes del mundo y, en particular, en América Latina en el período estudiado condujo a que se trazaran políticas públicas internacionales en torno a este hecho, que llevaron a que en 1994 se aprobara la Convención Interamericana Sobre Desapariciones Forzadas de Personas.

11 En Ese infierno, Elisa cuenta que fue obligada a trabajar en calidad de secuestrada de la Marina en la Cancillería y que su primer jefe fue El Duque, uno de sus torturadores, (Actis et al., 2006, p. 140). que nosotros no existíamos para el mundo... Quien está desaparecido siente que no sólo está desaparecido para los demás, para los que no saben de la existencia de los campos de concentración: está desaparecido para sí mismo. (Villani, 2011, p. 85)

Así nos dice Mario Villani, un físico, ex militante de la Juventud Trabajadora Peronista sobreviviente de cinco campos de concentración en donde permaneció por más de tres años en condición de desaparecido, en un libro publicado con Fernando Reati (2011) con base en entrevistas que este le hizo.

En el libro Ese infierno (2006), Elisa, estudiante de derecho y que terminó psicología social, menciona la alusión a la figura del desaparecido como una figura que se extiende a sectores más amplios de la sociedad, lo que nos evoca, a su vez, la canción de Fito Páez, Argentina la casa desaparecida ${ }^{12}$.

Somos una generación destruida y culposa. Nosotros estuvimos secuestrados o desaparecidos, y los que se quedaron en el país, escondidos, con miedo también, de alguna manera estaban desaparecidos... En 1986 me encontré con un compañero militante de Derecho. Nos abrazamos y yo me animé a contarle lo que me había pasado. Él me dijo: "Podés creer que yo me quedé en el país y vuelvo a caminar por Corrientes, después de doce años?". ¡Todos estábamos desaparecidos!

Para todos fue difícil adaptarse y enfrentar la realidad en esa época. Yo tengo amigos que no han pasado por la experiencia de ser un desaparecido $y$, sin embargo, por el sólo hecho de haberse quedado en el país de alguna manera estaban desaparecidos. Habían tenido distinto grado de compromiso en la militancia y tuvieron que cambiar su proyecto de vida. Era tanto el temor que los que habían simpatizado con la Jup dejaron la facultad y los que eran conocidos por su militancia en un gremio cambiaron de trabajo. (Actis, Aldini, Gardella, Lewin, y Tokar, 2006, pp. 81, 251)

La otra posibilidad es la de ser devuelto a la sociedad, estar formalmente bajo libertad y tener que empezar a rehacer la vida. ¿En qué condiciones subjetivas emergen estos individuos?, ¿qué posibilidades tienen de continuar con sus identidades políticas?, ¿qué tipo de acción política les exige el nuevo momento?, ¿a qué y hasta dónde están dispuestos a llegar respecto a los compromisos de luchar por el ideal que habían asumido previo a su detención?,

12 Como reza la canción de Fito Páez: "Argentina, Argentina qué pasó en la Argentina, es la casa desaparecida. Argentina, Argentina bienvenidos a casa Argentina, a la desaparecida". Disponible en: http://www.youtube.com/watch?v=3GOyKVaDi-o\&fe ature $=$ share \&list $=\mathrm{RDOnNjJr5llTc \& index=1}$ 
¿de qué modo las vivencias en los campos y en las prisiones incidieron en sus valores éticos, políticos y morales?, ¿a qué nuevas comunidades de adscripción política imaginaria podrían vincularse o contribuir a crear?

En el proceso de reconfiguración subjetiva en el momento presente, los desaparecidos/sobrevivientes deben someter, a través de su propio relato testimonial, sus vivencias y acciones a juicios éticos y políticos, los cuales están atravesados, necesariamente, por el contexto social y por las representaciones que circulan sobre estos acontecimientos, a las cuales han contribuido, entre otras, las narrativas testimoniales. Villani habla sobre los dilemas éticos y morales que se le presentaron en el cautiverio, enfatizando que este tipo de dilemas también atravesaron el conjunto de la sociedad argentina la que, al igual que muchos de sus individuos, estaba sometida al terror; dilemas que ponen en consideración referentes y repertorios culturales y políticos que inciden en la configuración subjetiva.

La vida en los campos estuvo plagada de dilemas: qué es lo correcto o lo incorrecto, dónde están los límites entre lo normal y lo aberrante, qué distingue a un torturador de un prisionero obligado a denunciar a sus compañeros... Pero los dilemas de los campos no fueron únicos: también el resto del país vivió situaciones aparentemente sin solución, como tener que adaptarse a vivir en dictadura o decidir no meterse cuando se llevaban a un vecino de noche. Esto es inevitable y resulta utópico pensar en una sociedad sometida al terror que no se enfrente a semejantes dilemas. (Villani, 2011, p. 162)

Munú, una artista muralista, quien después de su secuestro en la ESMA estuvo bajo libertad vigilada y obligada a continuar trabajando para los represores, menciona en Ese infierno la desestabilización que sufrió al perderse el lazo político por motivo de la detención y todo lo que ello implicó: "fue tan intensa la militancia que atravesó cada instante, cada lugar, cada circunstancia de nuestras vidas... Al quedarnos sin militancia, nos quedamos desorientados. Y había que rearmarse, rearmarse desde la derrota, desde la pérdida de los compañeros, desde la tragedia". (Actis et al., 2006, p. 250)

En general, las mujeres que testimonian en Ese infierno coinciden en que la experiencia de haber estado secuestradas en los campos clandestinos les significó la muerte de lo que habían sido hasta ese momento. A la vez insisten sobre los esfuerzos ingentes que les implicó superar esta experiencia y reconfigurarse como sujetos: ser otro ser.

Elisa: El sentimiento de derrota yo lo viví de una forma brutal. El hecho de haber estado con la capucha puesta tantos años fue mi derrota. Es verdad que pude construir mi familia, a la que amo profundamente y fue mi sostén durante todos esos años, pero no era ése mi proyecto de vida. Puedo surgir recién ahora, pero siento que soy una perdedora. A mí me mataron y de ahí surgió esta Elisa, más ligth, más liviana. (pp. 60-61).

Liliana: no te matan el cuerpo pero esto también es morir. Uno sigue funcionando, teniendo sensaciones, vivencias, emociones, deseos y sexualidad, pero todo ese funcionamiento atravesado por la pregunta de siempre: ¿Dónde estoy?, ¿qué hago con esto?, ¿quién soy? El plano ético es constante, todo el tiempo estoy pensando si lo que hago está bien o mal, y antes no me pasaba. (p. 61)

Munú: En la ESMA yo también sentí que me mataban. La que yo era murió. Es uno de los recuerdos de sensaciones que tengo más fuertes que tengo de todo el tiempo que estuve ahí dentro: sentí la muerte. De ese punto nunca se regresa totalmente. (p. 61)

Un interrogante que recorre muchos de los relatos de los sobrevivientes gira en torno a poder explicar y explicarse por qué quedaron con vida en medio de condiciones en las que desaparecieron tantos de los suyos, concordando que una de las razones estriba en el poder de escarmiento que el aparato represivo quería ejercer sobre el conjunto de la sociedad. Al respecto Villani dice:

¿Por qué hoy estoy vivo? No lo sé, no soy yo quien lo decidió. Puedo suponer dos razones: que les fui útil haciendo reparaciones eléctricas y mantenimiento, una colaboración que a mi entender no contrarió mis principios éticos; y que querían dejar a algunos de nosotros libres, siguiendo un criterio en gran medida azaroso, para que al salir nuestro relato difundiera el terror en la sociedad como parte de una metodología de control social. (2011, p. 165)

Con esta percepción también coincide Graciela Daleo, secuestrada en la ESMA, para quien el procesamiento sobre su sobrevivencia estuvo mediado por la vinculación a una organización política que agrupaba a ex detenidos que habían sido secuestrados en condición de desaparecidos, de este modo lo social ilumina lo individual:

Me acerco a la elaboración del "por qué estamos vivos" en la Asociación de Ex Detenidos-Desaparecidos. Comprender, entonces, que el diseño represivo incluía que quedara gente viva. Entender que mucha gente se lo pregunte, como yo también le habría preguntado a un sobreviviente de Auschwitz: ¿cómo duraste, cómo no te moriste, cómo no te mataron? Fue una pregunta muy angustiosa, 
me la hacía ahí adentro, porque además yo estaba convencida de que nos iban a matar a todos. Hubo distintos momentos para esa respuesta. Cuando salí en libertad, junto a otros compañeros, atribuíamos nuestra sobrevida y puesta en libertad a las particularidades de la ESMA. Después, al encontrarme con sobrevivientes de otros campos, en conjunto fuimos entendiendo y dándonos cuenta de las razones. Había sobrevivientes de distintos campos; de toda gran masacre hubo sobrevivientes. Viendo eso, llegamos a entender que quedamos vivos como parte de la voluntad de los represores que pretendieron hacer de nosotros predicadores del arrepentimiento y multiplicadores del horror. (Daleo, 2007, s. p.) ${ }^{13}$

Por su parte, Pilar Calveiro, en conversaciones con Juan Gelman, se refiere a la experiencia de su cautiverio y las transformaciones implicadas en el plano subjetivo en diferentes dimensiones y de qué modo las elaboraciones que hizo al respecto tuvieron como canal de expresión y reconfiguración subjetiva su tesis doctoral:

Haber pasado por la experiencia de los campos de concentración entrañó para mí una desestructuración profundísima en todos los órdenes. Yo era una persona, tal vez prototípica, de lo que fue $\mathrm{mi}$ generación en la Argentina, que sabía qué era lo que estaba bien, qué era lo que estaba mal, qué había que hacer en este mundo. Que además había logrado una coherencia importante: militaba, es decir, había confluencia entre lo que pensaba y lo que hacía, tenía una vida política y una vida personal en consonancia, una pareja militante como yo, y dos hijas. Todo estaba redondo, perfecto, cerrado. Pero en el año y medio que estuve en los campos fue como si me desarmaran todas las piezas del rompecabezas, como si patearan toda esa estructura. De modo que cuando salí me encontraba en una situación de vulnerabilidad muy fuerte... La tarea de sobrevivir no termina con la salida del campo de concentración. El sobreviviente se ve a sí mismo, o lo ven, o las dos cosas, se ve y lo ven, como alguien que sobrevive sobre otros que murieron. Es muy duro digerir eso. Este proceso fue difícil, duró muchos años, y me permitió en determinado momento concluir la tesis de la que forma parte el libro publicado, en el que se concentran mis ideas acerca del tema. (Gelman, 1998, s. p.)

13 Esta idea es también retomada en el libro de Bonasso, en e que se recrea una conversación entre el Tigre Acosta y Massera respecto al destino de los detenidos de la Esma destinados a sobrevivir en la que este último afirma: "Yo quiero conservar para el futuro a lo que llamo los Predicadores del Arrepentimiento... Acuérdese Acosta los Predicadores del Arrepentimiento". (Calveiro, 1984, p. 74)
La figura del traidor pende sobre los vivos y los muertos como un gran peso que corroe la confianza en los lazos políticos e incluso en los afectivos de las generaciones que se vieron afectadas por el terrorismo de Estado. Utilizada como una de las estrategias de los represores para desmoralizar a los militantes y a la sociedad en su conjunto, las narrativas dan cuenta de los ardides de los represores en los que se hacía pasar a prisioneros y secuestrados como informantes, hasta de sujetos que atravesaron por procesos de reconfiguración radical que se pasaron al bando de sus oponentes, contribuyendo en las sesiones de tortura o en planes de desmantelamiento de las organizaciones.

En cuanto a Chile, los textos de Luz Arce (1993) y Alejandra Merino (1993) dos militantes que ocupaban puestos de dirección en el MIR y que pasaron a colaborar con la DINA, el servicio de inteligencia de la represión, retratan con crudeza los resultados de la acción represiva sobre algunas de las subjetividades de los militantes, de las cuales la figura del traidor que además se reafirma públicamente como tal, es indicativa.

Para Argentina, novelas como Recuerdos de la muerte de Bonasso (1984) o El fin de la historia de Liliana Heker (2004) aluden a algunas de estas figuras. Estos textos son analizados por Longoni (2007) para auscultar de qué manera la figura del traidor, que rodea a los desaparecidos/sobrevivientes en Argentina, se ha tratado desde estereotipos construidos, en buena parte, desde las narrativas testimoniales. Para ello, Longoni analiza los códigos éticos de la militancia de los 70 en los que se inculcó la idea de que el sujeto militante no debía ser atrapado con vida, y en caso tal de que lo fuese debía tratar de quitarse la vida por cualquier medio. Así, quien permaneciese vivo en manos de los represores llevaba sobre sí la sospecha de la traición (p. 198). En el análisis de Longoni persiste, además, la idea de las dificultades que la sociedad tiene para escuchar y acreditar el testimonio de los sobrevivientes, que da cuenta de versiones de la historia que no son lineales, de militantes que no son solo héroes/mártires y de idearios políticos que habían empezado a debilitarse antes del golpe militar y que sin duda fueron derrotados por las fuerzas del régimen (p. 205).

Calveiro le menciona a Gelman, la intención que tuvo en su libro Poder y desaparición de que no solo se viese reflejada su experiencia, a la que solo alude en contadas ocasiones, sino que se pudiesen ver tanto las estrategias y formas de operar del poder concentracionario, como la diversidad de modos como los sujetos enfrentaron la represión, tanto dentro de los campos como, una vez, fuera de ellos. Sus palabras 
dejan ver algunas imágenes de esa multiplicidad de figuras de sujeto desplegadas en el período, las cuales se tejen y destejen en las narrativas testimoniales y arrojan luces y sombras sobre las configuraciones de los sujetos en la historia política reciente de América Latina.

La experiencia nos pegó a cada uno de manera diferente. Pero siento que en ese texto estamos todos, el que hizo borrón y cuenta nueva, el que se encerró en la familia o en una profesión, el que trata de dar cuenta de la historia, el que no puede deshacerse de ella y vive como sobreviviente eterno, el que habla, el que no habla, el heroico, el menos heroico, el que se rayó. Y ésta no es para mí una imagen mental, es una vivencia, la clara sensación de que cada uno de esos pedazos son pedazos míos, que mi propia historia está en cada una de esas historias. Eso no significa en absoluto que no haya responsabilidades, nada más lejos de mi intención. Pero sí quiere decir que cada uno de esos fragmentos nos interpela porque no nos son ajenos, porque hay una matriz concentracionaria que acuña muchas facetas de la sociedad argentina. Pensar lo contrario impide hacer lo que hay que hacer: comprender y procesar lo sucedido para marchar en una dirección inversa. No sé cuánto nos podremos alejar, ni el tiempo que eso lleve, tal vez sea cuestión de generaciones, pero necesariamente hay que marchar en la dirección opuesta. (Gelman, 1998, s. p.)

\section{Memoria y olvido: las tramas de la subjetividad}

Maldito mandato de la memoria, que no deja en paz a los vivos. Bendito mandato de la memoria, que constituye estructuralmente lo poco humano que sigue existiendo en el ser.

GOLDMAN (2012)

Quisiera olvidar pero el imperativo de recordar es más fuerte.

\section{VILLANI (2011)}

Los procesos de constitución de los sujetos y la configuración de sus subjetividades rebasan la voluntad del soberano motivo por el cual los sujetos que emergieron de estas experiencias límites, es verdad que habría que decir los que quedaron vivos, dejan entrever las posibilidades del ser humano para enfrentar situaciones extremas y experienciar procesos de dessubjetivación y de reconfiguración subjetiva, en los cuales se ponen en juego las trayectorias biográficas, los escenarios de formación, los proyectos políticos en contienda y las culturas políticas desplegadas, así como las coyunturas específicas en que estas situaciones tuvieron lugar.

Cuando la memoria individual se torna pública los sujetos anudan sus historias en las tramas colectivas (Pollak, 2006). Al poder afirmar la legitimidad de su existencia frente a los otros se reafirman individualmente, el desaparecido reaparece y dice yo estoy aquí, estuve en el infierno, pero sobreviví y lo que viví quiero compartirlo porque podría haber enseñanzas para la sociedad. Así parecen dejarlo entrever varios de los relatos testimoniales.

En el epílogo de Ese infierno se muestra cómo el colocar en la esfera pública la memoria personal significó para las autoras el reconocimiento social que da luz a sus vidas, una vez que sus experiencias personales adquieren un sentido colectivo.

La aparición del libro completo fue nuestra propia reaparición: dejamos de ser finalmente desaparecidas, nos habíamos sacado la capucha. Habíamos hundido el bisturí de la memoria lo más profundo posible, desnudando nuestras debilidades para que todos pudieran comprender que la realidad concentracionaria da lugar a comportamientos complejos, contradictorios. (Actis et al. 2006, p. 297)

O también cuando se empieza a hacer parte de procesos de denuncia ante las comisiones de verdad o ante los tribunales judiciales, el relato de la historia personal adquiere otras significaciones, como lo mencionan Munú y Elisa en Ese infierno:

Munú: Yo no sé si tengo la capucha entera, pero varios flecos seguro que tengo.

Elisa: A mí me sacudió el juicio a las Juntas, hizo que empezara a quitármela. Y a la vez me di cuenta de que no me acordaba de nada, sólo conocía algunos nombres de guerra y no podía asociarlos a las personas. Después de eso vino la angustia y el preguntarme para qué estaba viva, para qué me habían dejado vivir si estaba como muerta. En ese momento empecé a creer que me había matado a mí misma, me había autodestruido. Hasta que comencé a hacer terapia y así llegué a comprender que los marinos habían destruido una parte de mí... Cuando leí mi nombre en el diario por primera vez sentí que reaparecía.

Munú: ¿Cómo saliste de esa situación de angustia?

Elisa: Esos golpes son de por vida. Es tal el jaque a tu identidad, que es difícil encontrar una manera de reconstruirla. Aunque cada caso es diferente. (Actis et al., 2006, pp. 53, 81)

Mario Villani alude a la manera fragmentaria como trabaja la memoria respecto a los acontecimientos 
vividos y la función que el recuerdo y el olvido tienen en dicho trabajo, tanto en el plano de lo personal, para dar sentido y significación a lo vivido, como en lo relacionado con lo público, en donde la memoria se vuelve vital para la reconstrucción de los acontecimientos que conduzca a imputaciones legales o a interpelar las historias oficiales:

Cuando hablo de mis experiencias se me presentan pantallazos de cosas olvidadas y sepultadas en la memoria. Son imágenes o palabras, piezas de un rompecabezas que se arma en mi mente y de inmediato se desarma otra vez... Sin embargo, sobre todo me vuelven a la mente las cosas rutinarias. Ciertos recuerdos - como el impacto de la tortura- son imposibles de desterrar, pero otros se desvanecen. Puedo recordar cosas que me impresionaron mucho en su momento pero no recuerdo cómo me impactaron: sé que me hicieron sentir muy mal pero no puedo sentir ahora lo que sentí entonces.

Me gustaría poseer una memoria perfecta para conservar todos los detalles. Me angustia que eso no sea posible. Si bien puedo testimoniar sobre muchas cosas que pasaron y ofrecer una interpretación, me alejo cada día más de los hechos desnudos tal y como sucedieron. Como con las mamushkas rusas, esas muñecas que contienen adentro copias cada vez más pequeñas de sí mismas, el paso del tiempo convierte a la memoria en el recuerdo de un recuerdo... Tal vez es saludable que así sea. Con el paso del tiempo el olvido hace lo suyo y eso también es un tormento. ¿Olvidar es un pecado o una salvación? Quisiera olvidar pero el imperativo de recordar es más fuerte. (Villani, 2011, p. 161)

A continuación, mostramos cómo Villani procede a relatar las diferentes estrategias que puso en juego para luchar contra el olvido y la memoria fragmentada:

Desde que salí en libertad me propuse ayudar a que no se sepultara la memoria de lo ocurrido. Para eso debía empezar por reconstruir las identidades de las personas que vi en los centros clandestinos: a la mayoría sólo las conocía por sus nombres de guerra, ya que a los prisioneros no se nos permitía usar nuestros nombres sino apodos. Durante años llevé conmigo, a todas partes, un cuaderno de tapas duras donde anotaba cualquier información recogida en conversaciones o reuniones con otros sobrevivientes. (p. 149)

Cuando me reunía con sobrevivientes también intercambiábamos pedacitos de información. Era como armar un rompecabezas entre muchos jugadores, con el inconveniente de que cada uno tenía a lo sumo una pieza que los demás hasta entonces no habían visto: uno sabía el color de pelo de un torturador, otro le había escuchado decir que era de tal ciudad, un tercero podía reconocer su voz. (p. 150)

El imperativo de recordar, de ayudar a que no se sepulte la memoria de lo ocurrido, ha tenido en los sobrevivientes repercusiones de orden político, lo cual ha llevado a que se presenten a declarar ante los tribunales y, en muchos de los casos, a crear o a vincularse a organizaciones de defensa de derechos humanos, espacios que les han posibilitado su reconfiguración como sujetos políticos de nuevo cuño.

A partir de 1984 declaré en todo tipo de juicios. Desde que, ese mismo año, testimonié ante la Comisión Nacional por la Desaparición de Personas, no he cesado de hacerlo en tribunales del país y del extranjero. En 1985 testifiqué en el primer juicio contra los comandantes de la dictadura militar $y$, a partir de entonces, en innumerables procesos entablados por familiares de desaparecidos que conocí en los campos. (p. 154)

Al mismo tiempo, Villani se posiciona sobre cómo encarar en el presente lo referente a sus victimarios, señalando la importancia de llevar a cabo acciones políticas que impidan el surgimiento de regímenes totalitarios.

En cuanto a los que hoy están en el banquillo de los acusados, no siento rabia ni resentimiento hacia ellos... A lo sumo, desprecio: aquellos hombres se creían omnipotentes y hoy me parecen unos pobres diablos desnudos. Antes infundían temor con su sola presencia, ahora sólo repulsión. Son irrelevantes y nadie les tiene miedo. Me hicieron mucho daño y por culpa de ellos dejé partes de mi vida en el camino. Pero no los odio: odio, en cambio, el sistema que los hizo posibles. (p. 163)

El terror como herramienta de control social hace que se extiendan por la sociedad la indiferencia y el individualismo del "sálvese quien pueda": la impunidad de los responsables implanta la sospecha de todos sobre todos, no sabemos ya si el que se sienta a nuestro lado en el cine es un torturador. Estos regímenes volverán a generar torturadores cuando lo crean necesario. Por eso no alcanza con condenar a los represores del pasado: debemos poner fin a la existencia de los regímenes que necesitan la tortura para subsistir. (p. 166)

Los autores de las narrativas testimoniales hacen su apuesta en torno a que prevalezca en la memoria de los contemporáneos y de las nuevas generaciones los acontecimientos de violencia política. En esta medida, se han vinculado a movimientos por la memoria de diversa índole, poniendo a disposición sus aportes 
testimoniales, pero también dejando claro sus puntos de vista sobre las políticas de memoria oficiales y la serie de tensiones que se presentan en torno a la creación de monumentos y centros de memoria ligados a lugares donde operó la represión, incluidos los centros clandestinos de detención. Al referirse al Espacio de Memoria creado por las políticas kichneristas en la ESMA, las autoras de Ese infierno dicen:

Coincidimos en que el Espacio de Memoria debe ser proyectado con un alcance temporal que nos trascienda a los que atravesamos la experiencia concentracionaria... Pero a lo que no podemos renunciar es al reclamo de que en el Espacio de memoria esté cabalmente explicado el porqué de la lucha de la mayor parte de quienes fueron exterminados allí. Ellos eran el obstáculo para la implementación de un proyecto político y económico de dominación y exclusión que después, gracias a la feroz represión, se convirtió en el modelo vigente. (Actis et al., 2006, p. 302)

\section{Conclusiones: Y huirá la tristeza y el gemido ${ }^{14}$}

Las narrativas testimoniales al ubicarse en el plano de lo biográfico nos dejan entrever las distintas estrategias que tuvieron que desplegar los individuos y los grupos sociales para enfrentar las condiciones de violencia política que pusieron a prueba sus identidades individuales, sus referentes políticos, sociales y afectivos. Las condiciones de terror frente a fenómenos de persecución, confinamiento, tortura, desaparición, entre otras, fueron vividas tanto por los individuos como por el conjunto de la sociedad. Frente a estas situaciones, los sujetos atravesaron por procesos de des-subjetivación y de reconfiguración subjetiva en los que se pusieron en juego distintas posiciones de sujeto que logran ser rastreadas en la producción testimonial.

Del corpus documental analizado surge un abanico de narrativas que relatan experiencias individuales, que tratan de ser encuadradas en proyectos políticos de izquierda, o en idearios asociativos de tipo sindical, o en relatos que aluden a los quiebres subjetivos e identitarios, o en diversos aspectos que entran en la denominada zona gris en la que se borran las fronteras entre lo público y lo privado, lo real y lo irreal, el adentro y el afuera, la víctima y el victimario.

El campo cultural aunque desmantelado por las dictaduras, como bien lo ejemplifican las actas recientemente encontradas de la dictadura argentina,

14 Así titula Leon Rozitchner el prólogo a Ese infierno al cual aludíamos en las primeras páginas de este artículo. ha sido un campo fuerte y dinámico en Argentina y Chile, lo cual ha aparejado varias características. Por un lado, el que un porcentaje no despreciable de los detenidos/desaparecidos y exiliados fuesen intelectuales hizo que estos expresaran, a través de la escritura, la poesía, la pintura o el cine, las vivencias de la represión política, e, incluso, algunos que usualmente no hacían uso de estos recursos se vieron compelidos a acudir a la voz pública para reconfigurarse como sujetos, alimentando las memorias colectivas que, al cobrar mayor o menor circulación, han ido entretejiendo de distintas maneras los imaginarios sobre los fenómenos históricos acaecidos entre 1960 y 1990.

Son múltiples las comunidades políticas que pueden ser evocadas en los relatos cuyos repertorios entraron en juego en los procesos de subjetivación al interior de las organizaciones sociales, grupos guerrilleros, o vanguardias literarias o artísticas. Estas comunidades imaginarias eran más amplias que los grupos mismos y portaban memorias sobre el nuevo ser humano, el compromiso social y la militancia revolucionaria, que abrevaban en la Revolución Rusa, en la Revolución Cubana, en el mayo del 68, y tenían en común pensar que el capitalismo podía ser un régimen a derrotar en procura de otro que se consideraba más justo e igualitario.

En un artículo sobre la poesía elaborada en Chile entre 1975 y 1995, que alude de alguna manera a asuntos referidos al golpe de Estado de 1973 y sus implicaciones traumáticas en el plano personal y social, Sergio Mansilla señala cómo este tipo de poesía, que él denomina del contragolpe, jugó un papel importante en el campo cultural chileno, poniendo a circular otros sentidos sobre los acontecimientos históricos, que enriquecen el plano de las subjetividades y potencian las posibilidades de formación política.

En cualquier caso, la poesía del contragolpe funcionó como un espacio de libertad ante el peso de la coerción. Si concebimos la literatura como escenario de ficción donde ocurre (y/o puede ocurrir) aquello que no ocurrió antes en la realidad empírica de la historia ni ocurre ahora ni ocurrirá tal vez nunca, tendrá bastante sentido afirmar que se escribe poesía para hablar/construir un campo de realidad que incluye los deseos, los fracasos, los sueños y las pesadillas, las utopías y la violencia de la realidad sobre la imaginación (nótese que estoy usando el verbo hablar como transitivo). Así, al leer poesía, no aprenderemos propiamente historia en el sentido de apropiarnos de un cierto significado a través de la escritura lectura de una narración documental, verificable, "científica"; pero sí aprenderemos algo de las subjetividades que vivieron y sufrieron esa historia y cómo éstas fueron constituidas limitadas 
y potenciadas por la contingencia y las proyecciones simbólicas de ésta. Leer productos literarios de un período determinado es siempre leer refractariamente las fisuras de la historia, las fallas de lo real, asomarse a esas zonas que escapan del peso de los hechos y de su inteligibilización por la narración dominante del momento. (Mansilla, 2010, p. 7)

\section{Referencias bibliográficas}

Actis, M.; Aldini, C.; Gardella, L.; Lewin, M. y Tokar, E. (2006). Ese Infierno. Conversaciones de cinco mujeres sobrevivientes de la ESMA. Buenos Aires: Sudamericana.

Adorno, T. (1998). Educación para la emancipación. Conferencias y conversaciones con Hellmut Becker (19591969). Madrid: Morata.

Anderson, P. (1988). Democracia y dictadura en América Latina en la década del 70. Cuadernos de Sociología (2). Recuperado 18 de noviembre de 2013. Disponible en: http://politicalatinoamericana.sociales.uba.ar/ files/2011/05/anderson.pdf

Arce, L. (1993). El infierno. Santiago: Planeta.

Begué, M. F. (2002). Paul Ricoeur: La poética de sí mismo. Buenos Aires: Editorial Biblos.

Bonasso, M. (1984). Recuerdo de la muerte. México: Era Ediciones.

Calveiro, P. (2006). Poder y desaparición: los campos de concentración en la Argentina. Buenos

Aires: Colihue.

Carrasco, R. (1977). Prigué, Moscú: Novosti.

Cefaï, D. (2001). Expérience, culture et politique. En Cultures Politiques. (pp. 93-117). Paris: Presses Universitaires de France - PUF.

Costantini, H. (1984). La larga noche de Francisco Sanctis. Buenos Aires: Bruguera.

Costantini, H. (1984). De dioses, hombrecitos y policías. Buenos Aires: Bruguera.

Daleo, G. (marzo 22 de 2007). La mirada testigo. Lavaca. Recuperado el 15 de diciembre de 2013, disponible en: http://lavaca.org/notas/la-mirada-testigo/.

Daona, V. (2013). Mujeres, escritura y terrorismo de estado en Argentina: una serie de relatos testimoniales. Moderna Språk, 107 (2), 57-73. Recuperado el 14 de noviembre de 2013, disponible en: http:// ojs.ub.gu.se/ojs/index.php/modernasprak/article/ view/2654.

España, A. (1983). Dawson. Chile: Bruguera.
Feijóo, C. (2001). Memorias del río inmóvil. Buenos Aires: Clarín/Alfaguara.

García, V. (2013). Diez problemas para el testimonialista latinoamericano: los años '60-'70 y los géneros de una literatura propia del continente. Estudios de Literatura, (4), 368-405.

Gatti, G. (2008). El detenido-desaparecido. Narrativas posibles para una catástrofe de la identidad. Montevideo: Ediciones Trilce.

Gelman, J. (noviembre 1 de 1998). Pilar Calveiro describe la vida-muerte de los campos de concentración. "Una está en otra dimensión". Página/12. Recuperado el 17 de febrero de 2013, disponible en: http://www. pagina12.com.ar/1998/98-11/98-11-01/pag14.htm.

Giardinelli, M. (1984). Luna Caliente. Buenos Aires: Bruguera.

Goldman, D. (2012). Prólogo. En D. Tarnopolsky. Betina sin aparecer. Historia íntima del caso

Tarnopolsky, una familia diezmada por la dictadura militar. Buenos Aires: La Página S.A.

Heker, L. (2004). El fin de la historia. Buenos Aires: Suma de Letras.

Herrera, M. C. (2012). Memorias de la violencia política y narrativa testimonial: lecturas desde la historia cultural de la Educación. En R. H. Simões, J. G. Gondra. (Org.). Invenções, tradições e escritas da história da educação. (pp. 283-330). Vitória: EDUFES.

Herrera, M. C. (2013). Narrativa testimonial, políticas de la memoria y subjetividad en América Latina. Perspectivas teórico-metodológicas. En C. Piedrahita, Á. Díaz, P. Vommaro. (Comps.). Acercamientos metodológicos a la subjetivación política: debates latinoamericanos. (pp. 189-202). Bogotá: Universidad Distrital Francisco José de Caldas, CLACSO.

Huyssen, A. (2001). En busca del futuro perdido. Cultura y memoria en tiempos de globalización. México: Fondo de Cultura Económica.

Kordon, D. y Edelman, L. (1986). Efectos psicológicos de la represión política. Buenos Aires: Sudamericana - Planeta.

Lampasona, J. (2012). La figura del sobreviviente: en torno a las especificidades del genocidio en la Argentina. Una aproximación posible. Revista Afuera, VII (12). Recuperado el 20 de octubre de 2013, disponible en: http:// www.revistaafuera.com/print.php?id=269\&nro=12.

Lara, M.P. (1992). La democracia como proyecto de identidad ética. Barcelona: Anthropos. 
Longoni, A. (2007). Traiciones. La figura del traidor en los relatos acerca de los sobrevivientes de la represión. Buenos Aires: Editorial Norma.

López, F. (1984). El mejor enemigo. Buenos Aires: El Cid.

Mansilla, S. (2010). El paraíso vedado. Ensayos sobre Poesía Chilena del contragolpe (1975-1995). Santiago: LOM Ediciones.

Medina, E. (1984). Con el trapo en la boca. Buenos Aires: Galerna.

Merino, A. (1993). Mi verdad. Santiago: ATG.

Moraña, M. (1997). Documentalismo y ficción. Testimonio y narrativa testimonial hispanoamericana en el siglo XX. En Políticas de la escritura en América Latina. De la colonia a la Modernidad. (pp. 113-150). Caracas: Ediciones eXcultura.

Moreno, M. (enero 21 de 2000). Fisuras del poder. Página/12. Recuperado el 20 de noviembre de 2013, disponible en: http://www.pagina12.com.ar/2000/ suple/las12/00-01-21/nota1.htm.

Ochando, C. (1998). La memoria en el espejo: aproximación a la escritura testimonial. Barcelona: Anthropos.

Paoletti, M. (1993). A fuego lento. Murcia: Colección Carabelas.

Paoletti, M. (1999). Mala Junta. Buenos Aires: Editorial de Belgrano.

Peris Blanes, J. (2008). Historia del testimonio chileno. De las estrategias de denuncia a las políticas de la memoria. Quaderns de Filología LXIV. Valencia: Universitat de Valencia.

Prieto, M. (1999). Calle de las Escuelas No. 13. Buenos Aires: Libros Perfil.

Pollak, M. (2006). Memoria, olvido, silencio. La producción social de identidades frente a situaciones límite. La Plata: Ed. Al Margen.

Puig, M. (1976). El beso de la mujer araña. México: (s.e.).

Ramírez, F. (2002). Conflicto, democracia y culturas políticas. Iconos, Revista de FLACSO Ecuador. 15, 75-85.

Reati, F. (1992). Nombrar lo innombrable: violencia política y novela argentina (1975-1985). Buenos Aires: Legasa.

Reati, F. (2004). Trauma, duelo y derrota en las novelas de ex presos de la guerra sucia argentina. Chasqui, revista de literatura latinoamericana. 33, (1), 106-127.
Ricoeur, P. (1996). Sí mismo como otro. Madrid: Siglo Veintiuno.

Ricoeur, P. (1999). Historia y narratividad. Barcelona: Paidós.

Rozitchner, L. (2006). Y huirá la tristeza y el gemido. Prólogo. En Actis, M.; Aldini, C.; Gardella, L.; Lewin, M. y Tokar, E. Ese Infierno. Conversaciones de cinco mujeres sobrevivientes de la ESMA. (pp. 13-17). Buenos Aires: Sudamericana.

Schmucler, S. (2000). Detrás del vidrio. Buenos Aires: Siglo Veintiuno.

Silberstein, S. (2002). Bajo el mismo cielo. Buenos Aires: Sudamericana.

Soriano, O. (1982). Cuarteles en invierno. Buenos Aires: Bruguera.

Strejilevich, N. (1997). Una sola muerte numerosa. Miami: Letras de Oro.

Strejilevich, N. (2006). El arte de no olvidar. Literatura testimonial en Chile, Uruguay y Argentina entre los 80 y los 90. Buenos Aires: Catálogos.

Strejilevich, N. (2008). Anamnesis. En M. C. Sillato. Huellas. Memorias de resistencia. Argentina 1974 - 1983. (pp. 113-126). Argentina: Universidad Nacional de San Luis.

Tarnopolsky, D. (2012). Betina sin aparecer. Historia íntima del caso Tarnopolsky, una familia diezmada por la dictadura militar. Buenos Aires: La Página S.A.

Timerman, J. (1981). Preso sin nombre, celda sin número. Buenos Aires: Ediciones La Flor.

Todorov, T. (2000). Los abusos de la memoria. Barcelona: Paidós.

Valdés, H. (1974). Tejas Verdes. Diario de un campo de concentración en Chile.

Valenzuela, L. (1983). Cola de lagartija. Buenos Aires: Bruguera.

Villani, M. y Reati, F. (2011). Desaparecido. Memorias de un cautiverio. Club Atlético, el Banco, el Olimpo, Pozo de Quilmes y ESMA. Buenos Aires: Biblos.

Villegas, S. (1974). Chile, el estadio, los crímenes de la Junta Militar. Buenos Aires: Cartago.

Witker A. (1975). Prisión en Chile. México: FCE. 